\title{
SPONTANEOUS VARIATIONS OF THE SKIN POTENTIALS AND SKIN POTENTIAL REFLEXES DURING NATURAL SLEEP IN THE CAT
}

\author{
Yosizumi NirmI \\ Department of Neurophysiology, Institute of Brain Research, School of Medicine, \\ University of Tokyo, Bunkyo-ku, Tokyo, and \\ Laboratory of Psychophysiology, Department of Psychology, \\ Waseda University, Shinjuku-ku, Tokyo \\ Kisou Kubota AND Yoshiaki IwamuRA \\ Department of Neurophysiology, Institute of Brain Research, School of Medicine, \\ University of Tokyo, Bunkyo-ku, Tokyo
}

From recent extensive studies on sleep, it is now well established with cats that there occur two distinct phases in sleep: sleep with slow waves and spindle burst in the EEG (ortho-sleep, etc.), and sleep with low voltage fast waves in EEG (para-sleep, etc.) ${ }^{2,4,18)}$.

A number of papers have been concerned with the variations in skin potentials (GSRs) during sleep in human subjects, $1,6,7,10-14,16,17)$. A few others were concerned with spontaneous variations in the intact chronic animals during sleep.15). This paper describes in cats spontaneous variations of the GSRs, as well as evoked from the peripheral nerve with respect to two different phases of the sleep.

\section{METHODS}

A total of 13 adult cats were used. Details of preliminary operative procedures and experimental conditions were described in the previous paper8). The GSRs were recorded from the forelimb paw pads and the dorsum of each paw, using zinc disc electrodes (approximately $1 \mathrm{~cm}$ in diameter) with zinc sulphate-kaolin paste. They were attached by adhesive vinyl tape. The time constant of the amplifier was infinity or $1.5 \mathrm{sec}$. The EEG recordings were from the somato-sensory area with brass screws drilled into the calvaria, and also from the hippocampus by a conventional bipolar stainless needle. The EMG was from the posterior cervical muscles using two stainless steel needles. The eye movements were by two small brass screws drilled into frontal bones near the supraorbital arch. The collar type silver electrode8) was attached to

Received for publication May 16, 1967.

新美良純, 久保田競, 岩村吉晃. 
the peroneal nerve in order to evoke the GSRs of the forelimb pads. The peroneal shock was a pulse of $0.1 \mathrm{msec}$. duration with less than $3 \mathrm{~V}$, and repeated at $0.3 \mathrm{cps}$. The animal was in a small box, as described in the previous paper ${ }^{8)}$.

The para-sleep was identified by typical activities of low voltage fast pattern of the neocortical EEG, $\theta$-rhythm of the hippocampus, rapid eye movement, and silence of the neck EMG.

\section{RESULTS}

Spontaneous GSRs. The spontaneous GSRs were recorded in the intact unrestrained states without applying any noticeable stimuli. The para-sleep episodes were observed for 81 times in total.

In FIG. 1, together with the somato-sensory EEG, eye movement, and neck EMG, the typical variations of the spontaneous GSRs were shown. In an awake state (upper left), the spontaneous GSRs appeared relatively frequently, being often associated with body movements as noted from the EMG records. In ortho-sleep state (upper right), they appeared sporadically and moderately in frequency with relatively regular intervals. In para-sleep state (lower),
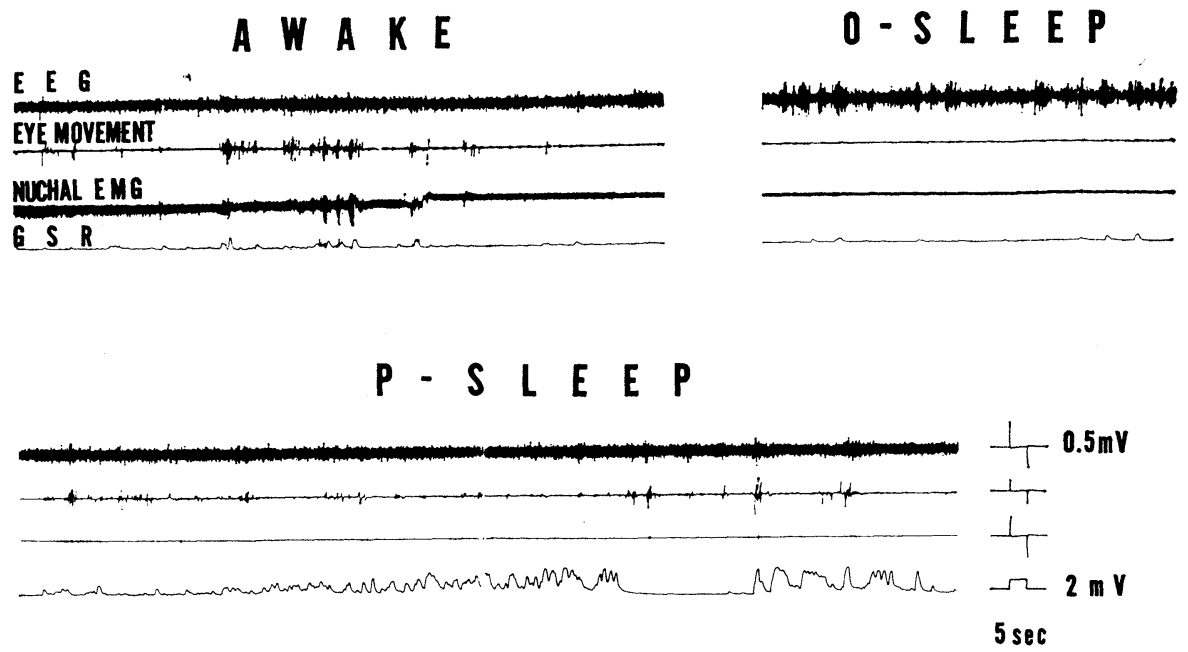

FIG. 1. The spontaneous GSR and sleep. From top to bottom, are the neocortical EEG, eye movement, nuchal EMG, and GSR from the left paw pad. Upper left: awake. Upper right: ortho-sleep. Lower: para-sleep. Calibrations are indicated at right bottom.

spontaneous GSRs underwent striking change. For two-thirds of the para-sleep episodes (55 observations of 9 cats) fewer GSRs were present during this stage of sleep than those during preceding or succeeding awake and ortho-sleep states. And in one-third (26 observations of 4 cats) a special temporal pattern was noted, that is, spontaneous GSR bursts with small amplitude lasting from 
$10 \mathrm{sec}$. to $1 \mathrm{~min}$. These bursts preceded and/or followed by a complete silence of relatively longer periods, as seen in the lower trace of FIG. 1. Usually this pattern appeared once or twice in each para-sleep episode. In a most frequent case, seven GSR-bursts were counted during one episode. Such trains of GSRs were never seen in ortho-sleep nor in an awake state. This did not associate in time with other signs of para-sleep, such as the rapid eye movement, or twitch like movements of the vibrisse and forearms.

The above mentioned features of para-sleep GSRs were compared between ortho-sleep and para-sleep in a graphic form (FIG. 2). The intervals between two successive GSRs (T) were measured and the frequency histogram of the intervals was made for each state. In this example, intervals longer than $4 \mathrm{sec}$. were observed in para-sleep but not in ortho-sleep, while the intervals less than $0.5 \mathrm{sec}$. were more frequent in ortho-sleep. During para-sleep the longer intervals were observed in 80 percent and the shorter ones in 60 percent out of 81 para-sleep episodes.

FIG. 3 contrasts changes of the occurrence of the spontaneous GSR (numbers/min.), and their amplitudes (algebraic sum of the amplitudes/min.) between ortho- and succeeding para-sleep in all observed episodes. Values during ortho-sleep are represented by white bars and values during para-sleep by black bars. In the middle of the figure is shown the time in min. occupied by para-sleep. Though the rate of occurrence of GSRs are quite variable in each instance in these sleep states, both frequency and amplitude tended to decrease during para-sleep. It seems that there is no significant relation between GSR decrease and length of each para-sleep episode.

Evoked GSRs. The GSRs evoked by the peroneal nerve stimulation were recorded in 26 sleep periods of 7 cats. The stimulus was fixed at an intensity strong enough to awaken the animal in ortho-sleep during several initial single shocks. FIG. 4 illustrates the evoked GSRs. The GSRs appeared with a fixed latency of about $1 \mathrm{sec}$. in an awake state (upper left). When the background EEG activity changed to the spindle burst pattern (upper right), the occurrence of evoked GSRs decreased. During para-sleep, as seen in the lower trace of FIG. 4, complete absence of the GSR evocations at the left was succeeded by the continuous, summating evoked GSRs. This change during para-sleep was seen only in 4 episodes out of 26 episodes. And in 13 cases, GSRs were not evoked at all or became less elicitable during para-sleep. In the other 9 cases comparisons were not possible, because the GSRs quickly habituated after several initial responses and never reappeared throughout the whole observation period, irrespective of the state of the animal. 


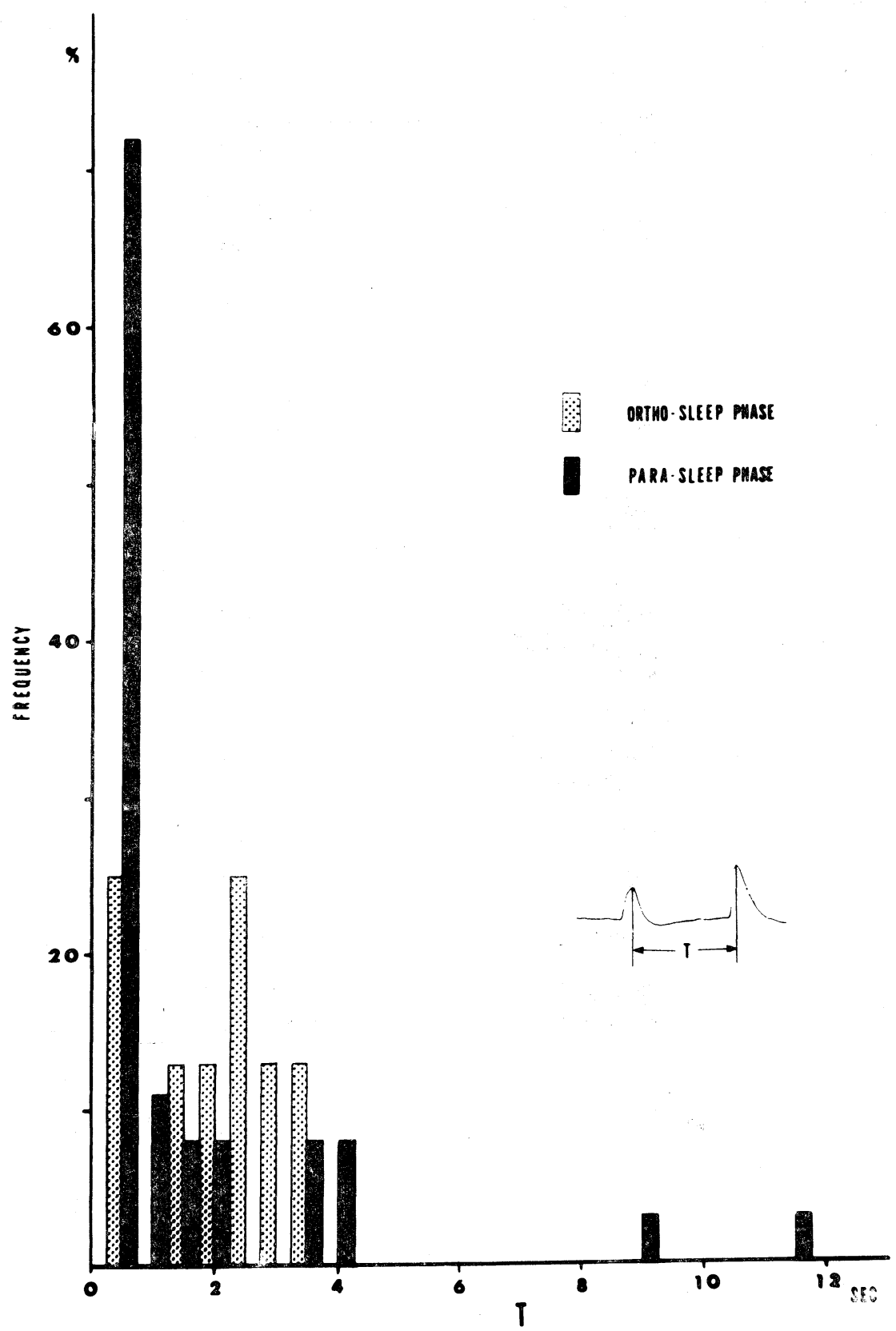

FIG. 2. Frequency histogram of intervals ( $T$ ) between two successive spontaneous GSRs, during the preceding ortho-sleep (dotted bar), and succeeding parasleep (black bar) phases. Insert indicates the way of measuring the time in sec. (T). 


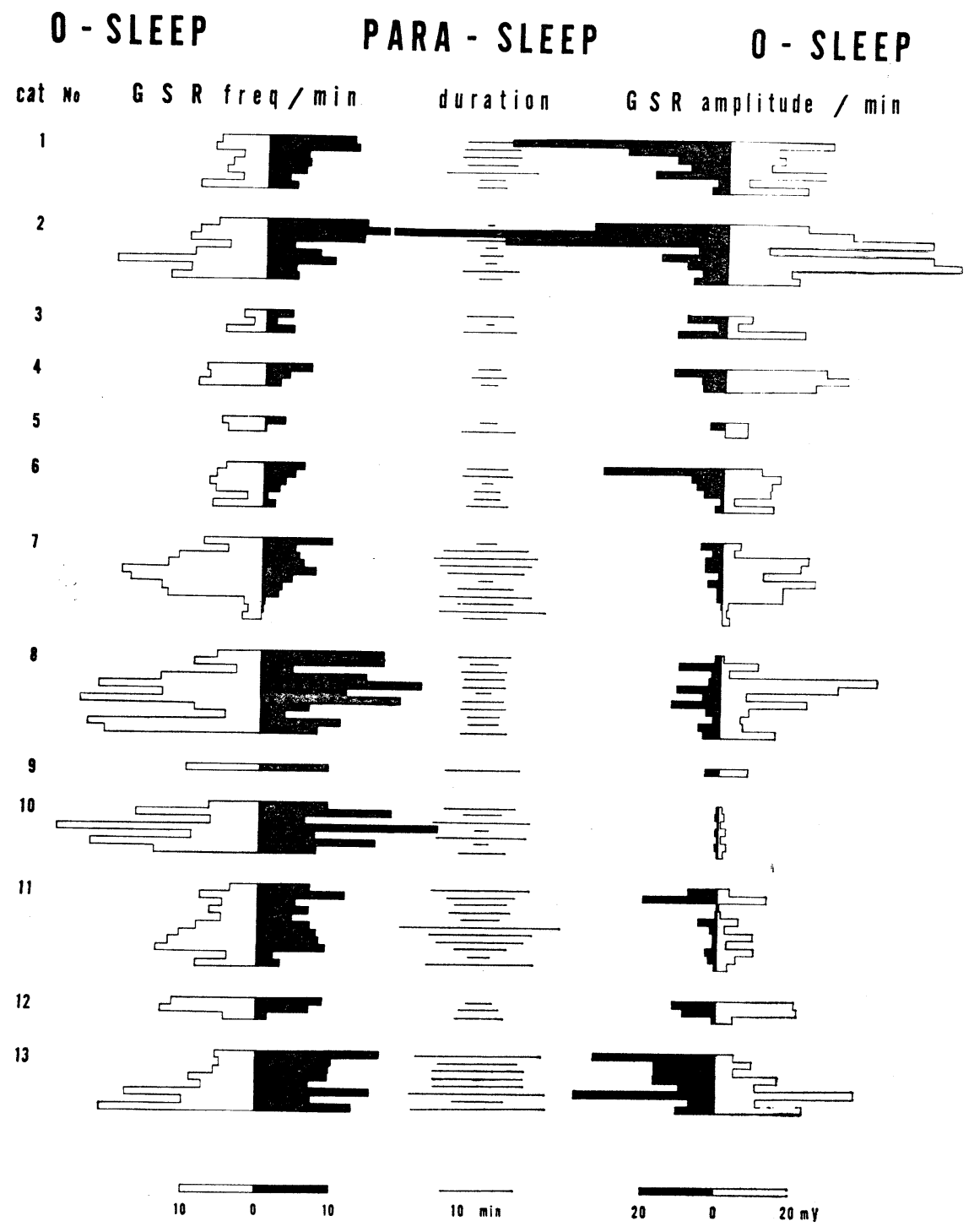

FIG. 3. Changes of occurrence of GSRs in respect to both frequency and amplitude during transitions from ortho- to para-sleep. All 81 observations are summarized. Center thin lines : duration of para-sleep in min. Left bars : frequency of GSRs per min. Right bars: sum of amplitudes of GSRs in $\mathrm{mV}$. per min. In amplitude measurement the response of more than $0.8 \mathrm{mV}$ was included. Black bars indicate para-sleep and white bars ortho-sleep as a control. Measurements. were from immediately preceding ortho-sleep of the same time length and the succeeding para-sleep. 
GSR AND SLEEP

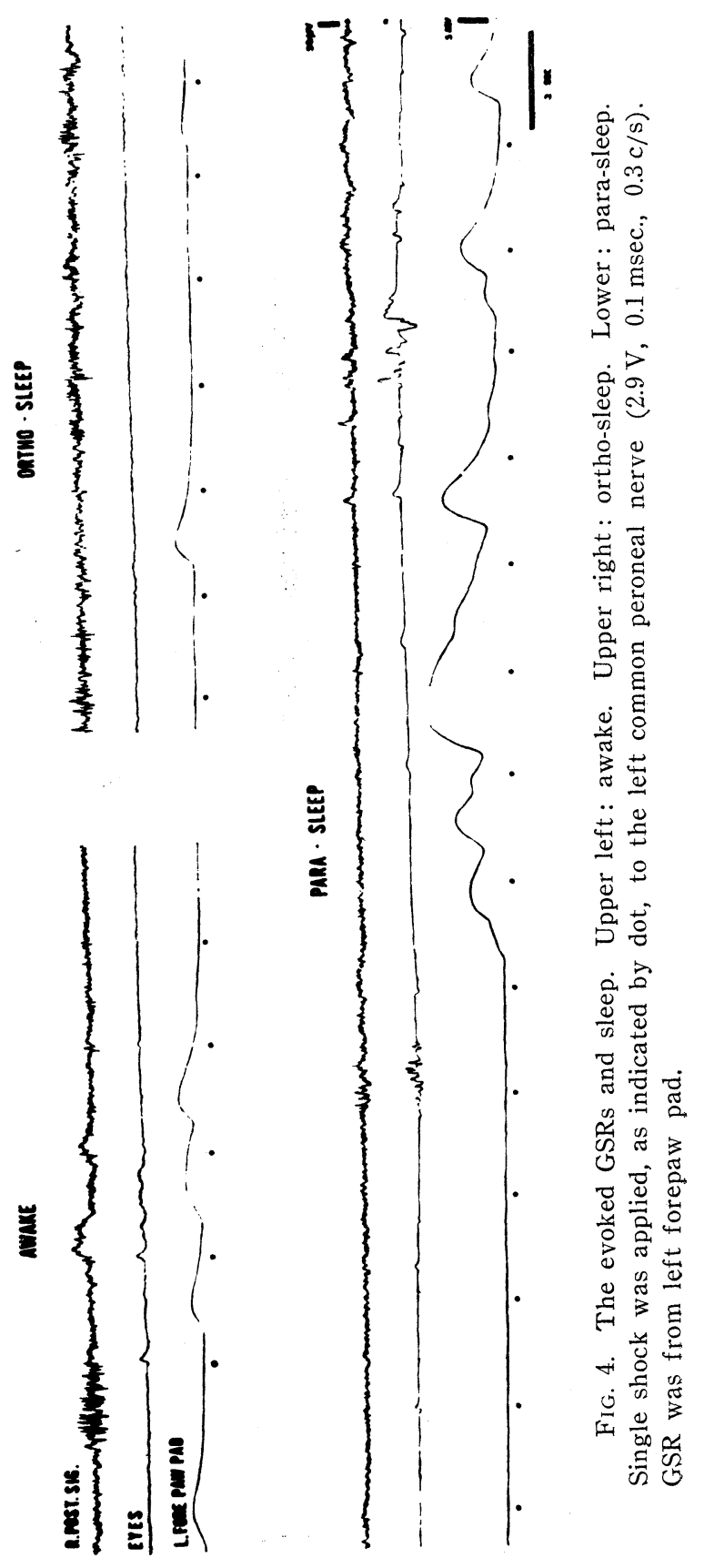




\section{DISCUSSION}

The enhancement of occurrence of spontaneous GSRs during para-sleep, characterized with burst-like multiple waves of small size was seen in approximately 30 percent of the cases. Similar increase in the evoked GSR from the mixed nerve was seen in 24 percent of cases. The spontaneous GSR activities of the palmer surface are generally accepted, with one exception ${ }^{16}$, to be more prominent during ortho-sleep than during para-sleep in cats $^{15)}$ and human subjects ${ }^{1,3,6,7,14)}$. With respect to the evoked GSRs during sleep, BROUGHTON et al.1) gave auditory or visual stimuli to human subjects and noted that the threshold for provoking GSR greatly increased during para-sleep compared with ortho-sleep. OKUMA et al. ${ }^{11}$ reported that the amplitude of evoked GSRs by photic stimuli became smaller during para-sleep than during the preceding ortho-sleep phase. Results of the present study are consistent with these, in both spontaneous and evoked GSRs.

$K_{O G A}{ }^{7)}$ recently reported that burst-like GSRs, continuous for several minutes, sometimes appeared during para-sleep. BROUGHTon et al. ${ }^{1)}$ also described that the para-sleep stage may contain fairly frequent GSRs, often in a long train fashion associated with frequent bursts of rapid eye movement. In the present study, however, the occurrence of GSR bursts associated with bursts of rapid eye movement during para-sleep was not confirmed.

Similar to the blood pressure change ${ }^{5,18)}$, it is concluded that there are dual influences to the skin potential during para-sleep, tonic depressive and transient facilitatory. These two did not necessarily appear in the same episode of para-sleep, even in one cat.

\section{SUMMARY}

Both spontaneous and evoked GSRs were compared at different phases of the sleep (para-sleep and ortho-sleep) in unrestrained chronic cats. The GSRs were recorded from the forelimb paw pads, using zinc with zinc sulphate electrodes.

In 68 percent of 81 cases with 13 cats the number of spontaneous GSRs decreased during the para-sleep phase rather than during ortho-sleep phase, while in 32 percent it increased. The increased cases were characterized by a burst pattern composed of continuous small potentials continuing for 5 to $60 \mathrm{sec}$.

In the ortho-sleep phase, stimulation of peroneal nerve fibers evoked GSRs occasionally, while in the para-sleep phase, periods of complete silence and/or those of successive evocations appeared alternately. 


\section{REFERENCES}

1) Broughton, R. J., Poire, R. And Tassinari, C. A., (1965); The electrodermogram: (Tarchanoff effect) during sleep. EEG clin. Neurophysiol., 18: 691-708.

2) DEMENT, W., (1958); The occurrence of low voltage, fast, encephalogram patterns during behavioral sleep in the cat. EEG clin. Neurophysiol., $10: 291-296$.

3) Johnson, L.C. ANd Lubin, A., (1966); Spontaneous electrodermal activity during: waking and sleeping. Psychophysiology, 3: 8-17.

4) Jouvet, M., (1962); Recherches sur les structures nerveuses et les mécanismes. responsables des différentes phases du sommeil physiologique. Arch. ital. Biol., $100: 125-206$.

5) Kanzow, E., Krause, D. And Kuhnel, H., (1962); Die Vasomotorik der Hirnrinde in den Phasen desyncronisierter EEG Aktivität im näturlichen Schlaf der Katze. Pflügers Arch. ges. Physiol., 274 : 593-607.

6) KogA, E., (1960); The study of sleep by polygraph, I: Normal sleep. Psychiat. Neurol. Jap., 62: 125-148. (Japanese with English synopsis)

7) KogA, E., (1966); EEG and GSR during human sleep. Clin. Psychiat. (Japan), 8 : 182-188. (Japanese)

8) Kubota, K., Iwamura, Y. and Nimi, Y., (1965); Monosynaptic reflex and natural. sleep in the cat. J. Neurophysiol., $28: 125-138$.

9) Ninm, Y., Kubota, K. And Imamura, Y., (1963); GSRs and PSRs in the so-called paradoxical sleep state. Proc. XIIth annu. Meet. Jap. EEG Soc., 206.

10) Ogawa, T., Satoh, T. And Takagi, K., (1967); Sweating during night sleep. Jap. J. Physiol., $17:$ 135-148.

11) Okuma, T., Nakamura, K., Hayashi, A. and Fujimori, M., (1966); Psychophysiological study on the depth of sleep in normal human subjects. EEG clin. Neurophysiol., $21: 140-147$.

12) Okuma, T., Nakamura, K., Hayashi, A. and Fujimori, M., (1966); Polygraphic: study of sleep-With special reference to the depth of sleep. Advanc.neurol. Sci. (Japan), $10: 113-122 . \quad$ (Japanese)

13) Oswald, I., (1959); Experimental studies of rhythm anxiety and cerebral vigilance. J. ment. Sci., $105: 269-294$.

14) Oswald, I., (1962); Sleeping and Waking, Elsevier Publ. Co., Amsterdam.

15) Roy, J.C. AND Bloch, V., (1966); Activité électrodermale en relation avec les. stades de sommeil chez le Chat chronique. J. Physiol. (Paris), 58: 261-262.

16) TIZARD, B., (1966); Repetitive auditory stimuli and the development of sleep. EEG clin. Neurophysiol., 20 : 112-121.

17) TIZARD, B., (1966); Evoked changes in EEG and electrodermal activity during. the waking and sleeping state. EEG clin. Neurophysiol., $20: 122-128$.

18) Tokizane, T., (1965); Studies on the paradoxical phase of sleep in the cat. In T. Tokizane and J.P. Schadé (Eds.); Progress in Brain Research, Elsevier Publ. Co., Amsterdam, Vol. 21 B, 230-268. 